Bente Jacobsen*

\title{
Pragmatic Meaning in Court Interpreting: An empirical study of additions in consecutively interpreted question-answer dialogues
}

\section{Introduction}

My $\mathrm{PhD}$ thesis investigates the interpreting process in criminal proceedings in Danish district courts. The investigation centres on questionanswer dialogues, that is, the questioning of defendants and witnesses by judges, prosecutors and defence counsels.

The interpreters in my investigation were authorized interpreters and therefore competent professionals fully aware of trial procedures and the role of participants. The mode of interpreting was the consecutive mode: The interpreter took notes while the primary participant was speaking and delivered her interpretation of his utterance after he had finished speaking. The interpreting was bi-directional, and the two languages involved were Danish and English.

\section{Point of departure}

The point of departure for my investigation has been the conflict between, on the one hand, the official perception of the court interpreter as a kind of 'translating machine', which simply transfers language products from one language to another, and, on the other, the reality of the interpreting situation in the courtroom, where mechanical translations may result in miscommunication.

\footnotetext{
* Bente Jacobsen

Department of English

The Faculty of Language and Business Communication

Fuglesangs Allé 4

DK-8210 Aarhus $V$

BJ@asb.dk
}

Hermes, Journal of Linguistics no. 32-2004 
Interpreted courtroom dialogues are conducted face-to-face and are essentially three-party transactions, involving two primary speakers and one interpreter. The immediacy of the face-to-face encounter and the sensitive nature of the interaction are bound to exert considerable influence not only on the production of source texts, but also on the production of the interpreter's target texts. Nevertheless, ethical guidelines generally instruct court interpreters to provide verbatim translations of original utterances. Thus, in Denmark, the guidelines for interpreter behaviour, which are laid down in the document Instructions for Interpreters $^{1}$, instruct court interpreters to translate speakers' originals "using the same words and phrases, whenever this is possible". As a result, the guidelines are generally perceived as instructing interpreters to produce word by word translations of speakers' originals, unless there are specific reasons, such as language differences, why such translations may be impossible.

Two facts in particular provide evidence that court interpreters tend to be regarded as a mechanical devices:

(1) Court interpreters are not expected to prepare for their assignments to any great extent, and they are not expected to need dictionaries, law books, etc.

(2) Participants in courtroom proceedings generally regard interpreter competence as being measurable by comparing the number of words in a speaker's original utterance to the number of words in the interpreter's translation of his utterance. In other words, if there seems to be a discrepancy between the length of a source text and the length of its corresponding target text, this is regarded as evidence of interpreter incompetence.

Cecilia Wadensjö (1998: 7) points out in her study of dialogue interpreting in Sweden that this general perception of the interpreter is very much influenced by a 'transfer' model of communication, what

1 Instructions for Interpreters was published by the National Commissioner of the Danish Police (Rigspolitichefen) in 1994 and is directed at police interpreters only. However, the document constitutes the only official guidelines for interpreters in Denmark, and it is generally regarded as applying to court interpreters also. 
Michael Reddy (1979) called the conduit model of communication. A similar observation is made by Ian Mason (2000: 218) in his article on dialogue interpreting research. According to Reddy's model, communication consists of transporting definable entities from producer to receiver via a process of decoding and re-encoding. So, laypersons tend to think of interpreters as conduits, or as channels, through which prepared messages go back and forth. Indeed interpreters often think of themselves in this manner.

Throughout my thesis, I argue that the general perception is wrong. I argue that court interpreters do not function as mere transporters of other people's words, but play a much more active part in the communication process in the courtroom than is generally expected.

\section{Hypotheses}

Based partly on previous court interpreting research, and partly on my own experiences as a practising court interpreter as well as discussions with some colleagues in the field, I established the following two hypotheses:

(1) The actual behaviour of court interpreters will show evidence of a preoccupation with pragmatics, that is, with building a mental model of speaker meaning and with conveying this mental model to end receivers, and

(2) as a result of this preoccupation, their target texts will contain a variety of additions.

In other words, I hypothesized that the primary objective of court interpreters is successful interaction; they are aware that, in order for this objective to be reached, participants will have to fully understand each other's intentions. The interpreters instinctively judge that, by providing merely verbatim versions of speakers' originals, they will not bring about such understanding, since end receivers who are unfamiliar with the context (linguistic and/or situational) of the interaction will not be able to fully infer speaker meaning. In order to compensate for the lesser inferencing ability of end receivers, therefore, the interpreters adopt a strategy for conveying source texts which will ensure that a 
speaker's communicative intention, and not only his words, is available to an end receiver.

A brief look at some aspects of the background of the investigation will serve to illustrate this further:

Danish courts base their decisions on oral presentations only, that is, on statements and witness testimonies, which means that, as a rule, documents and statements will have to be read out in court in order to be considered evidence. This is known as the principle of orality, and it emphasizes the crucial role of spoken discourse and therefore the importance of obtaining proper statements and witness testimonies.

The setting of the investigation, a courtroom, is controlled and agenda-bound. Trial procedure, including the procedure for extracting statements and witness testimonies, is governed by Danish law (The Administration of Justice Act), which provides that questions must be precise, unambiguous and explicit, so that defendants and witnesses will know exactly what is required of them and will be able to provide the requested information. Courtroom participants generally assume that this provision prevents misunderstandings, but questions are in fact not always precise, unambiguous or explicit, and answers do not always seem to provide the requested information. In other words, even in courtroom interaction, a speaker's communicative intention is not always easily available, especially to an end receiver who is unfamiliar with the context of the interaction.

Consequently, a court interpreter will often find herself in a situation when she cannot reach her objective of successful interaction and comply with the ethical guidelines at the same time. I hypothesize that, when an interpreter finds herself in such a situation, her objective of successful interaction will override her attention to official guidelines or the perception of primary participants.

\section{Data}

The collected data were recorded at two trials, a mock trial and a simulated trial. The alleged offence in the mock trial was rape, and the witness at that trial was also the alleged victim of rape. The alleged offence in the authentic trial was fraud; the defendant had allegedly purchased a large number of items in various shops in Copenhagen with the aid of stolen credit cards. Finally, this defendant did not have English as a 
mother tongue, but he had specifically requested an English interpreter, since, or so he said, he had lived in Great Britain for most of his life and was fluent in English.

The data collection process was extremely complicated. Of course, collecting data for interpreting research is generally a very difficult process, as many researchers will attest to (e.g. Dam 1995: 95; Gile 1995: 20 21). First of all, it is often extremely difficult to get permission to record interpreted interaction, and, secondly, interpreters don't always like to have their target texts recorded and scrutinized. In addition, interpreted courtroom interaction is a relatively new and under-researched object of study, especially in Denmark where my investigation is the first of its kind. So, I had to assume right from the beginning that the collection of authentic data presented a serious challenge, for two reasons:

(1) Though court hearings in Denmark are public, as a rule, the legal system tends to exhibit caution when it comes to the publication of details from a hearing, especially from a criminal trial, where the rights of defendants or victims have to be considered. Also, as a rule, the recording or transmission of sound or sounds from a court hearing is prohibited.

(2) Since my investigation is the first of its kind in Denmark, I had to assume that interpreted proceedings in a criminal trial had never been recorded for the purpose of analysis. This meant that I would have to find a way of convincing the legal system of the benefits of allowing the publication of details from trials for research purposes.

As a result, the data collection process involved a large number of considerations and practical issues, from getting access to proceedings to choosing the right recording equipment. Almost 2,5 years went by before I was able to collect authentic data, and in the meantime I resorted to staging the mock trial.

Of course, now that I am able to put the enormity of the task behind me, I am thrilled that I was actually able to collect authentic courtroom data. Moreover, since my investigation has shown that it is in fact possible to record interpreted courtroom interaction for research purposes without obstructing proceedings or violating the rights of 
participants, and without hindering the interpreting process, I have presumably managed by my efforts to pave the way for a lot more studies of court interpreting in the years to come.

\section{Method}

In order to test the two hypotheses presented earlier, I set out to answer the following four research questions:

(1) Will the target texts of the court interpreters in my investigation include a variety of additions?

(2) If so, can the additions identified in the interpreters' target texts be categorized?

(3) If categories are established, will these then indicate the court interpreters' motives for including the identified additions in their target texts?

(4) If motives are indicated by the established addition categories, may these then be linked to a preoccupation with pragmatics on the part of the court interpreters?

So, having recorded and transcribed interpreted question-answer dialogues at the two trials referred to above, I answered the first research question by conducting a source-text/target-text comparison of the collected data. This analysis identified a large number of additions in the court interpreters' target texts.

I then answered the second research question by registering the identified additions according to their impact on the semantic and/or pragmatic content of the source text. This enabled me to establish three main categories and a number of subcategories. Also, since I collected the mock data first, I initially based the categories and subcategories on findings from an analysis of those data, and then tested them through an analysis of the authentic data.

Having established addition categories, I answered the third and fourth research questions by applying to the investigated interaction the pragmatic theory of conversational implicature, which was proposed by the philosopher Herbert Grice $(1975,1978,1981)$, and which provides 
a framework for analysing how hearers infer speaker meaning. I set up a basic model accounting for implicature in question-answer dialogues in criminal proceedings, and I discussed eight strategies that a court interpreter may be assumed to resort to when confronted with implicature in an original utterance.

I also discussed the implications of the inference process for court interpreters, applying the notion of audience design proposed by Allan Bell (1984), which distinguishes between different receiver groups and their influence on a text producer's style.

Finally, by matching Grice's theory and the various assumptions to the established categories and subcategories of additions, I was able to reach certain conclusions regarding the interpreters' motives for including the identified additions in their target texts.

\section{Addition categories}

The various categories and subcategories of additions identified in the collected data are presented in Table 1: 
Table 1: Additions identified in the collected data²:

\begin{tabular}{|c|c|c|}
\hline \multirow{4}{*}{$\begin{array}{l}\text { Additions with no impact } \\
\text { on the semantic and/or } \\
\text { pragmatic content of the } \\
\text { source text }\end{array}$} & \multicolumn{2}{|l|}{ Repetitions } \\
\hline & \multicolumn{2}{|l|}{ Silent pauses } \\
\hline & \multicolumn{2}{|l|}{ Voice-filled pauses } \\
\hline & \multicolumn{2}{|l|}{ False Starts } \\
\hline \multirow{7}{*}{$\begin{array}{l}\text { Additions with minimal } \\
\text { impact on the semantic and/ } \\
\text { or pragmatic content of the } \\
\text { source text }\end{array}$} & \multicolumn{2}{|l|}{ Repetitions $_{\mathrm{p}}$} \\
\hline & \multicolumn{2}{|l|}{ Fillers $_{p}$} \\
\hline & \multicolumn{2}{|l|}{ Paralinguistics $_{\mathrm{p}}$} \\
\hline & \multirow[t]{3}{*}{ Explicating additions } & Obvious-information additions \\
\hline & & Connective additions \\
\hline & & $\begin{array}{l}\text { Additions explicating } \\
\text { non-verbal information (mock } \\
\text { trial)/ } \\
\text { explicating culture-bound } \\
\text { information (authentic trial) }\end{array}$ \\
\hline & \multicolumn{2}{|l|}{ Elaborating additions } \\
\hline \multirow{3}{*}{$\begin{array}{l}\text { Additions with significant } \\
\text { impact on the semantic } \\
\text { and/or pragmatic content of } \\
\text { the source text }\end{array}$} & \multicolumn{2}{|l|}{ Emphasizing additions } \\
\hline & \multicolumn{2}{|l|}{ Down-toning additions } \\
\hline & \multicolumn{2}{|c|}{ New-information additions } \\
\hline
\end{tabular}

The first main category registers additions which I judged to have no impact on the semantic and/or pragmatic content of the source text. These additions were identified as features typical of normal conversation. Such features may generally be attributed to the particular nature of spoken interaction, requiring fast, almost instantaneous production and understanding. Therefore, I presumed that their presence in the interpreters' target texts could be attributed to the special nature of the interpreting process, also requiring fast, almost instantaneous production and understanding, but this time in two different languages. Probably, the additions functioned mainly as disguised translational repairs, that is, as stalling devices (cf. Stenström 1994: 76) meant to 'buy'

2 This model was inspired by Anne Schjoldager's (1996: 110) model of target-text/ source-text relations. 
the interpreters time to process inputs and prepare outputs. In any case, since the additions had no impact, I did not considered them relevant for the purpose of my investigation, and I identified and categorized them purely for elimination purposes.

The second main category registers additions which I judged to have minimal impact on the semantic and/or pragmatic content of the source text. The first three subcategories of additions in this category I identified as having potential impact only, marked with a ${ }_{p}$.

Additions registered as belonging to the subcategory of Explicating additions explicitly expressed information which was implicitly present in the context of the interaction. I divided this subcategory into three more subcategories: Obvious-information additions, Connective additions, and Additions explicating non-verbal information (identified only in the mock data) or Additions explicating culture-bound information (identified only in the authentic data). These subcategories are illustrated in example 1 (additions are underlined):

Example 1:

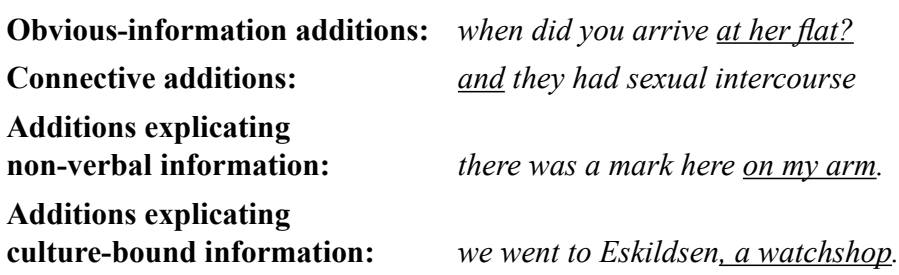

Finally, the fifth subcategory of additions, Elaborating additions, registers additions which elaborated on items that had already been rendered once in an interpreter's target text. I shall also illustrate this subcategory by an example:

Example 2:

Elaborating additions: did you feel intoxicated? did you feel drunk

The third main category registers additions which I judged to have significant impact on the semantic and/or pragmatic content of the source text. These additions introduced information, either explicitly or implicitly, into the interaction for the first time. Again, I shall exemplify the different subcategories: 


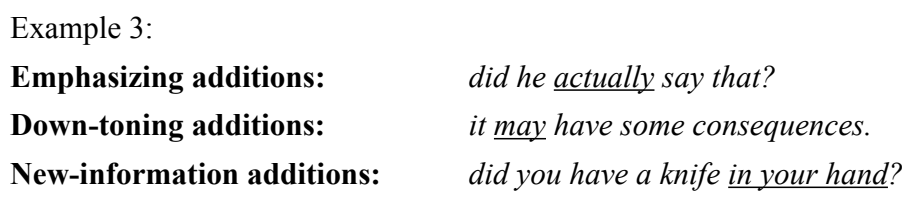

As demonstrated in Table 1, the same categories and subcategories of additions were identified in both kinds of data, with the aforementioned exceptions: the subcategory of Additions explicating non-verbal information, which occurred only in the mock data, and the subcategory of Additions explicating culture-bound information, which occurred only in the authentic data. Neither subcategory occurred more than once, but this fact may be insignificant, for two reasons:

(1) Non-verbal information only had to be interpreted once at the mock trial, and culture-bound information of the kind explicated by the interpreter in the authentic trial did not occur in the mock trial; and

(2) non-verbal information did not occur in the authentic trial, and culture-bound information was generally explicated by the speaker, which meant that the question of whether or not the end receiver would be able to infer the information did not arise very often.

However, I regard as significant the fact that, apart from these two subcategories, all other categories and subcategories of additions were identified in both kinds of data. Clearly, the established categories and subcategories must be considered valid categories and subcategories. Consequently, the findings from the two data analyses not only demonstrate that additions do occur in court interpreting, but they also demonstrate that not all additions have equal impact on the semantic and/or pragmatic content of the source text.

\section{Interpreter motives}

My discussion of the court interpreters' motives for including the identified additions in their target texts focused on the categories of Additions with minimal impact and Additions with significant impact. Thus, I did not discuss the interpreters' motives for including additions with no impact, for the reasons outlined earlier. 
As regards additions with minimal impact, I argued that, with the exception of additions with potential impact which, like additions of no impact, could be attributed to the special nature of the interpreting process, additions with minimal impact were included for the specific purpose of making speakers' intentions available, or more easily available, to end receivers. In other words, Explicating and Elaborating additions were triggered by the interpreters' instinctive judgment that end receivers who were unfamiliar with the context of the interaction would need assistance to infer speaker meaning.

I further argued that additions with significant impact were included for a similar reason. Thus, I argued that the first two subcategories of additions, Emphasizing additions and Down-toning additions, were included for the specific purpose of directing end receivers' attention to information which was implicitly present in the context of the original utterance and which had to be inferred (in the case of Emphasizing additions) or verified (in the case of Down-toning additions) in order for speaker meaning to be available. In other words, the interpreters included these additions based on their instinctive judgment that end receivers would not be able to spot the presence of implicit information, but would be able to infer it once it was spotted.

Finally, I argued that the last subcategory of additions with significant impact, New-information additions, were included because the interpreters selected interpretations of source texts which included this information. The fact that the interpreters occasionally selected interpretations of utterances which did not appear to match what could be derived from the originals could likewise be explained by reference to their preoccupation with building and conveying a mental model of speaker meaning. So, though I was not able to explain these additions by reference to the interpreters' instinctive judgment of end receivers' ability to retrieve speaker meaning, I was still able to link the interpreters' motives for including them to their preoccupation with pragmatics.

\section{Conclusion}

Following my discussion of interpreter motives, I was able to conclude that the presence of additions in the target texts of the court interpreters in my investigation could be explained by reference to their preoccupation 
with matching speakers' utterances to relevant aspects of context and with ensuring the retrievability of speaker meaning. Thus, I concluded that the actual behaviour of the court interpreters provided evidence of a preoccupation with pragmatics, and, in turn, that my findings served to support the hypotheses.

Further support for my conclusion was presented by the various examples of implicature that I found in the data. I did not systematically register implicatures, since I only registered implicatures that occurred in connection with one or more interpreter additions with either minimal or significant impact. However, the court interpreters conveyed these implicatures by adopting strategies which either explicated, or partly explicated, them. Thus, it seems that the interpreters' choice of strategy for conveying implicature was likewise triggered by their instinctive judgment concerning the inferencing ability of end receivers who were unfamiliar with the context of the interaction.

Finally, my conclusion was supported also by three kinds of interpreter behaviour that I observed in the collected data:

(1) The interpreter who assisted the defendant in the authentic trial invariably corrected his grammatical errors,

(2) all three interpreters completed fragmented source texts as a rule, and

(3) all three interpreters engaged in dialogue with the foreign participants who requested repetition or clarification of source texts in Danish.

The three kinds of behaviour demonstrated not only that the interpreters were preoccupied with pragmatics; they also demonstrated that the interpreters were prepared to violate ethical guidelines in order to achieve their primary objective of successful interaction.

In conclusion therefore: The court interpreters in my investigation did not function as mere mechanical devices, simply transferring language products from one language to another. On the contrary, they participated actively in the communication process in the courtroom in order to reach their primary objective of successful interaction. 


\section{Sources}

Bell, Allan 1984: Language style as audience design. In Language in Society, 13, $145-$ 204.

Dam, Helle V. 1995: Tekstkondensering i foredragstolkning. Formel og sproglig analyse på grundlag af spansk-danske tolkninger. Unpublished PhD Thesis submitted to the Faculty of Modern Languages, the Aarhus School of Business.

Gile, Daniel 1995: Interpretation Research: A New Impetus? In Hermes, Journal of Linguistics, 14, 15-29.

Grice, Herbert 1975: Logic and Conversation. In P. Cole and J.L. Morgan, eds, Syntax and Semantics 3: Speech Acts. New York: Academic Press, 41-58.

Grice, Herbert 1978: Further Notes on Logic and Conversation. In P. Cole, ed., Syntax and Semantics 9: Pragmatics. New York: Academic Press, 113-127.

Grice, Herbert 1981: Presupposition and Conversational Implicature. In P. Cole, ed., Radical Pragmatics. New York: Academic Press, 183-198.

Instruks for Tolke (Instructions for Interpreters), November 1994. Copenhagen: The National Commissioner of the Danish Police (Rigspolitichefen), E. Dept.

Mason, Ian 2000: Models and Methods in Dialogue Interpreting Research. In M. Olohan, ed., Intercultural Faultines. Research Models in Translation Studies I. Textual and Cognitive Aspects. Manchester: St. Jerome Publishing.

Reddy, Michael 1979: The Conduit Metaphor: A Case of Frame Conflict in our Language about Language. In A. Ortony, ed., Metaphor and Thought. Cambridge: Cambridge University Press, 284-324.

Retsplejeloven (The Danish Administration of Justice Act). Most recently amended version is that of 14 September 2001.

Schjoldager, Anne 1996: Simultaneous Interpreting: Empirical Investigation into Target-text/Source-text Relations. Unpublished PhD Thesis submitted to the Faculty of Modern Languages, the Aarhus School of Business.

Stenström, Anna-Brita 1994: An Introduction to Spoken Interaction. London/New York: Longman.

Wadensjö, Cecilia 1998: Interpreting as Interaction. Longman. 
